\title{
Exposure to vibrations in wine growing
}

\author{
Domenico Pessina, Davide Facchinetti \\ Dip. di Scienze Agrarie e Ambientali, Università degli Studi, Milano, Italy
}

\section{Abstract}

Apart the winter period, the activity in specialized agricultural cultivations (i.e. wine- and fruit-growing) is distributed for a long period of the year. Some tasks, such as pesticide distribution, are repeated several times during the growing season. On the other hand, mechanization is one of the pillars on which is based the modern agriculture management.

As a consequence, in wine growing the tractor driver has to be considered a worker potentially subjected to high level of vibrations, due to the poor machinery conditions often encountered, and sometimes to the rough soil surface of the vineyard combined with the high travelling speed adopted in carrying out many operations.

About vibrations, the Italian Decree 81/08 basically refers to the European Directive 2002/44/CE, that provides some very strict limits of exposure, both for whole body and hand-arm districts.

In Oltrepo pavese, a large hilly area located the south part of the Pavia province (Lombardy - Italy) wine growing is the main agricultural activity; for this reason, a detailed survey on the vibration levels recorded at the tractor driver's seat was carried out, in order to ascertain the real risk to which the operators are exposed.

The activity in wine growing has been classified into 6 groups of similar tasks, as follows:

1. canopy management: pruning, trimming, binding, stripping, etc.;

2. soil management: harrowing, hoeing, subsoiling etc.;

3. inter-row management: chopping of pruning, pinching, grass mowing, etc.;

4. crop protection: pesticides and fungicides distribution, sulfidation, foliar fertilization, etc.;

5. grape harvesting: manual or mechanical;

6. transport: from the vineyard to the cellar.

For each group of tasks, the vibration levels on 3 the traditional axes ( $\mathrm{x}, \mathrm{y}$ and $\mathrm{z}$ ) were recorded, and then an exposure time was calculated for each of them, in order to ascertain the risk level in comparison to what provided by the dedicated standard.

Finally, a detailed study was conducted on the most dangerous work-

Correspondence: Domenico Pessina, Dip. di Scienze Agrarie e Ambientali, Università degli Studi, v. Celoria, 2 - I 20133 Milano, Italy.

domenico.pessina@unimi.it

Key words: vibration risk, exposure, tractor, implement, wine growing

CC Copyright D. Pessina and D. Facchinetti, 2013

Licensee PAGEPress, Italy

Journal of Agricultural Engineering 2013; XLIV(s2):e135

doi:10.4081/jae.2013.s2.e135

This article is distributed under the terms of the Creative Commons Attribution Noncommercial License (by-nc 3.0) which permits any noncommercial use, distribution, and reproduction in any medium, provided the original author(s) and source are credited. ing conditions, with the goal to offer solutions able to reduce the overall exposure, as improving the comfort level, as to shorten the working time when possible and/or to provide suitable periods of rest.

\section{Introduction}

In Europe, the evaluation of the vibrations risk is based on 2002/44/EC Directive, implemented by time in Italy and confirmed in the Decree $81 / 08$, dealing with the safety and comfort of the workers. Also the Machine Directive provides that manufacturers must minimize the vibrations hazard adopting for their production a suitable design and usage conditions. Moreover, in the operation and maintenance manual of a given machine the values of the weighted acceleration of vibration must be reported.

In particular, the Decree 81/08 provides that employers are compelled to ascertain the level of whole-body and hand-arm vibrations in the tasks carried out by the employees under his/her responsibility. For whole-body vibrations, the exposure limits referred to a 8-hours working period are $0,5 \mathrm{~m} / \mathrm{s} 2$ for the action value and $1,0 \mathrm{~m} / \mathrm{s} 2$ for the limit value. As an alternative, to the figures indicated by manufacturers in the operation and maintenance manual, information about the vibrations levels can be found in dedicated databases. Unfortunately, the vibration values included in the databases often do not report with a sufficient level of detail the operating condition of the tasks, such a s the soil or road surface characteristics, the travelling speed, the tyre inflation pressure, the type and the wear of the seat fitted on the machine and its suspension system, etc. They all are factors influencing remarkably the vibrations level and therefore the operator's exposure. In practice, if reliable data are not available, a direct measurement should be carried out, in accordance with the most known dedicated standards, issued by ISO and CEN, or referring to national guidelines. Moreover, all parameters affecting the operator's level of risk have to be taken into account: axis of perception, frequency, exposure time and obviously vibrations level.

The daily exposure value $A(8)$ normalized to 8 hours must be calculated in accordance with ISO 2631-1, based on the higher of the Root M ean Square (RMS) values of the frequency-weighted accelerations determined on 3 orthogonal axes (awx, awy, awz) for a worker sitting or standing.

For agricultural tasks, the vibrations risk cannot be easily ascertained, because of several sources of disturbance and a very wide variability of operation modes. Therefore, the risk assessment is still often poorly reliable.

In tractors, in addition to the engine, the main vibration sources appear to be the gearbox and the vehicle travelling, due to the rolling/sliding of the tyres/track on the ground, especially if hard and bumpy.

The lack of literature data for a standardized approach to the problem and the need to integrate the existing databases with suitable information, led to the execution of a survey on the exposure to vibrations of agricul tural employees in Oltrepo Pavese, a large area particularly suited to wine growing. The measurements were carried out in 
collaboration with other local institutions (ASL, U00ML, Maugeri Foundation).

\section{Materials and methods}

In order to find the technical meaning of the levels magnitude variation (the range between min and max), 6 groups of common tasks carried out in wine growing have been defined. Also taking into account the machinery characteristics and the operating conditions, the groups were divided as follows:

1. canopy management: pruning, trimming, binding, stripping, etc.;

2. soil management: subsoiling, harrowing, hoeing, etc.;

3. inter-row management: trimming, pruning, suckering, grass mowing, etc.;

4. crop protection: sulfidation, distribution of pesticides and fungicides, foliar fertilization, etc.;

5. grape harvesting: manual or mechanized;

6. transport: mainly from the vineyard to the cellar.

The measurements were performed in 11 wine farms located in Oltrepo pavese. The vibration levels were recorded thanks to a vibration meter make Larson Davis model HVM100, complying the ISO 8041:1990 requirements and a tri-axial accelerometer make PCB model ICB $356 \mathrm{~B} 41$ (mass $11 \mathrm{~g}$, sensitivity 10,2 mV/ms-2) placed on the tested tractor seats.

The measurements time was different considering the task features; in any case, the duration, from a minimum of 3 min was defined in order to assure the maximum significance to the data acquired. A dedicated software was then developed to calculate the single axis and the overall levels.
The complementary data, relevant to the task carried out and the machines used have been collected in some paper forms, filled directly in the field. In particular, information about the tractor and the implement technical features, the soil and the working conditions were included (tab. 1).

The table is based on 6 sections, as follows:

- the single task taken into account;

- the test location;

- the main technical features of the tractor and the implement(s);

- the soil conditions and the travelling speed;

- the vibrations levels obtained and the corresponding time of measurements:

- the single axis and the overall levels of vibration.

A general database was finally built, to obtain a overall overview on the survey carried out (tab. 2)

\section{Results and discussion}

The standards actually in force provide that the highest of the weighted vibration level recorded on the 3 axes (max (1.4 awx, 1.4 awy, awz) has to be considered as a reference. On the other hand, the dedicated literature highlights an alternative solution, i.e. the RMS value of the levels obtained on each of the 3 axes $\left(\square(1.4 \mathrm{awx})^{2}+(1.4\right.$ $a w y)^{2}+a w z^{2}$.

The difference between the two methods is more remarkable as the individual values differ from each other; on the contrary, the two results are fairly similar if the single values are nearly close.

In any case, at present there is no still agreement on which method is able to represent better the effective disturbance. For this reason,

Table 1. An example of the paper form filled in the field for one group of the tasks surveyed.

\begin{tabular}{|c|c|c|}
\hline Chain: & \multicolumn{2}{|l|}{ WINE GROWING } \\
\hline Task: & \multicolumn{2}{|l|}{ PRUNING D } \\
\hline \multicolumn{3}{|l|}{ Wine farm ref.: } \\
\hline Date: & \multicolumn{2}{|l|}{ Operator(s): } \\
\hline Tractor: & make: model: & maxpower: ___ kW __ CV wheeldrive: 2WDO 4 WDO \\
\hline Driver's seat: & \multicolumn{2}{|l|}{ suspension type : } \\
\hline Implement: & \multicolumn{2}{|l|}{ towed $\mathrm{Q}$ 3-point hitched $\mathrm{Q}$} \\
\hline \multicolumn{3}{|l|}{ Working conditions } \\
\hline 1-Tool type: & \multicolumn{2}{|c|}{ vertical blade $\mathrm{Q}$ horizontal blade $\mathrm{Q}$ other (specify): __ $\mathrm{Q}$} \\
\hline 2-Soil condition: & $\begin{array}{l}\text { FAVOURABLE (wet or dry } \\
\text { sandy soil; no gravel or } \\
\text { stone content; no or light } \\
\text { compaction) } \mathrm{a}\end{array}$ & \begin{tabular}{|l|l|} 
NTERMEDIATE (clay-sandy-loam \\
ioil; low gravel and stone content, & $\begin{array}{l}\text { POOR (clay and dry soil; high } \\
\text { gravel and stone content; high } \\
\text { surface and deep } \\
\text { compaction) d compaction) } \mathrm{D}\end{array}$ \\
\end{tabular} \\
\hline 3-Terrain surface: & smooth (i.e. lawn) & airly rough (i,e,wheat stubble) \\
\hline 4-travelling speed: & low $(<5 \mathrm{~km} / \mathrm{h})$ & nedium $(5-8 \mathrm{~km} / \mathrm{h})$ \\
\hline \multicolumn{2}{|c|}{ Measured vibration level: $X$ axis (lat): $\ldots \mathrm{m} / \mathrm{s}^{2}$} & $\mathrm{Y}$ axis (long.): $\ldots \mathrm{m} / \mathrm{s}^{2}$ \\
\hline Measuring time: & $x$ axis (lat.):___ min & $Y$ axis (long.): __ min \\
\hline Value1 & \multicolumn{2}{|c|}{$\max \left(1,4^{*} X ; 1,4^{*} Y ; Z\right)=\ldots \mathrm{m} / \mathrm{s}^{2}$} \\
\hline Value 2 & \multicolumn{2}{|c|}{$\sqrt{(1,4 * X)^{2}+(1,4 * Y)^{2}+(Z)^{2}=\ldots \mathrm{m} / \mathrm{s}^{2}}$} \\
\hline \multicolumn{3}{|l|}{ Note: } \\
\hline
\end{tabular}


Table 2. Example of database sheets created for the data management and processing.

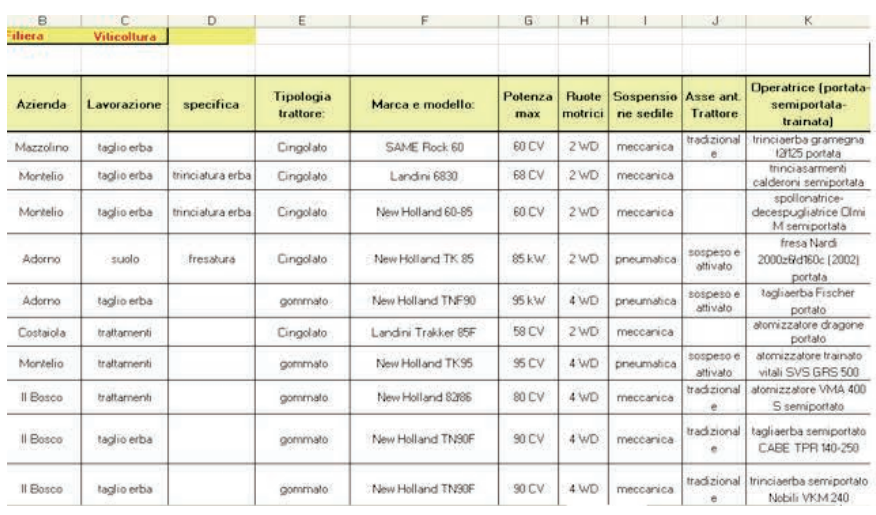

the vibration levels obtained with the two methods were compared. In fig. 1 the differences in percentage were shown: for all the 6 groups of similar tasks for the "old" RMS method higher values were calculated, ranging the increases from 26 to $35 \%$. The transport was the more significant task, because when travelling at high speed the levels in all the axis are similar, and therefore the "old" RMS level is much higher than that of the highest among the single axes. In fact, other than the vertical axis ( $\mathrm{z}$ ), also the vibrations in the horizontal axes ( $\mathrm{x}$ and $\mathrm{y}$ ) are similarly high, due to the disturbance caused by the trailer (in the longitudinal axis) and the roughness of the road (in the lateral axis).

\section{Analysis for groups of similar tasks}

The tasks performed in the canopy management (fig. 2) show the highest values in the vertical axis, being the more involving a hazard for the spinal column. In particular, the 4 cases surveyed were referred to trimmers coupled with tractors ranging from 60 to $100 \mathrm{CV}$. The lowest values (case 2) was referred to a wheeled tractor, while in the others 3 crawler tractors were considered. The $\mathrm{z}$ (vertical) axis showed values very close to or exceeding $1 \mathrm{~m} / \mathrm{s}^{2}$, the limit value. In the horizontal axes the levels were less hazardous. The vibrations were generated by the travelling of the tractor on the rough soil, while the movement of the trimming blades do not caused significant disturbance.

The vibrations about the soil management tasks (fig. 3) are quite low in two cases, but remarkably high in the other two. The tasks concerned the harrowing and hoeing, but it must be taken into account that all the implements were coupled the crawler tractors having a power ranging between 62 and $115 \mathrm{CV}$. In particular, the harrowing

\begin{tabular}{|c|c|c|c|c|c|c|c|c|c|c|c|c|}
\hline \multirow{2}{*}{\multicolumn{2}{|c|}{ 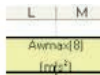 }} & \multicolumn{2}{|c|}{$N_{\text {Imax ore }} 0$} & \multicolumn{3}{|c|}{$P|O| A$} & $s$ & T & \multirow[t]{2}{*}{10} & \multicolumn{3}{|c|}{$|w| x$} \\
\hline & & \multirow{2}{*}{$\begin{array}{c}\begin{array}{c}\text { Livello di } \\
\text { aziens }\end{array} \\
0.5\end{array}$} & \multirow{2}{*}{$\begin{array}{l}\begin{array}{l}\text { Valcre } \\
\text { limite }\end{array} \\
1.15\end{array}$} & \multicolumn{3}{|c|}{ Volori in $\mathrm{mes}^{2}$} & \multirow[b]{2}{*}{$\begin{array}{c}\text { sup. } \\
\text { terreno }\end{array}$} & \multirow[b]{2}{*}{ terreno } & & \multicolumn{3}{|c|}{ Valori in min } \\
\hline \begin{tabular}{|l} 
dopo \\
it 2002 \\
\end{tabular} & \begin{tabular}{|c} 
prima \\
del \\
2002 \\
\end{tabular} & & & awx & awy & awz & & & velocita & $\begin{array}{c}\begin{array}{c}\text { Iempo di } \\
\text { rilevazione } \\
\text { awx }\end{array} \\
\end{array}$ & $\begin{array}{c}\text { tempo di } \\
\text { rilevazione } \\
\text { awy }\end{array}$ & \begin{tabular}{|c}
$\begin{array}{c}\text { tempo di } \\
\text { rilevazion } \\
\text { awz }\end{array}$ \\
\end{tabular} \\
\hline 0,43 & 0.64 & $28 \mathrm{~h}$ & $28 \mathrm{~h}$ & 0.23 & 0.37 & 0.34 & amogenes & favorevole & bassa & $\pi 45$ & w & 2328 \\
\hline 0.70 & 0.91 & 4 & $28 \mathrm{~h}$ & 0.23 & 0.34 & 0.7 & irregolize & sfavorevole & bassa & 1343 & 1328 & 2747 \\
\hline 1.07 & 1.18 & 2 & $28 \mathrm{~h}$ & 0.27 & 0.23 & 1.07 & itregdere & sfavorevide & bosso & $T$ & 628 & 1401 \\
\hline 0,35 & 0,50 & $28 \mathrm{~h}$ & $38 \mathrm{~h}$ & 0.13 & 0.25 & 0.31 & & sfavorevole & bassa & & & $z$ \\
\hline 0.44 & 0.69 & $88 \mathrm{~h}$ & $28 \mathrm{~h}$ & 0.28 & 0.25 & 0,44 & amogenes & fovorevole & medis & & & $z$ \\
\hline 1,74 & 2,19 & 1 & 3 & 0.6 & 0.73 & 1.74 & omogereas & fascorevole & meds & 1709 & tros & 1709 \\
\hline 0.73 & 1.03 & 4 & $28 \mathrm{~h}$ & 0.35 & 0.52 & 0.54 & amogenea & favorevele & medis & 2729 & $2 \pi 29$ & $2+29$ \\
\hline 0.98 & 1.26 & 2 & $28 \mathrm{~h}$ & 0.7 & 0.43 & 0.51 & amogerea & stavorevole & media & 4 & 4 & 4 \\
\hline 0.87 & 1.13 & 3 & $28 \mathrm{~h}$ & 0.62 & 0,38 & 0.49 & amogenea & sfavorevale & bases & $\pi 47$ & $\pi 47$ & 1147 \\
\hline
\end{tabular}

(cases 3 and 4) showed higher levels in respect to the hoeing (cases 1 and 2); this is because the tine harrow produces more vibration than the hoe and also because the harrowing is normally executed at a higher travelling speed in respect to the hoeing. In fact, in cases 3 and 4 (harrowing) the highest value were recorded in the vertical axis. This is the typical situation of the vehicle travelling at high speed on a rough surface.

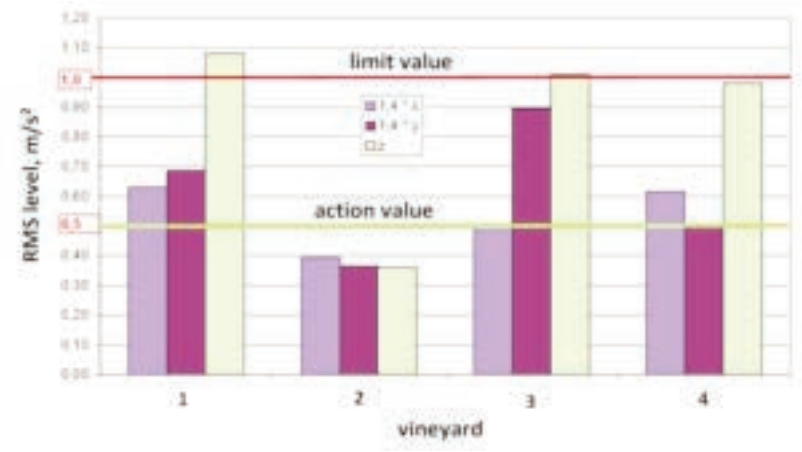

Figure 2. Vibration levels recorded in axes $x, y, z$ during the trimming, carried out with a wheeled tractor (case 2) and 3 crawler tractors (cases 1, 3 and 4$)$.

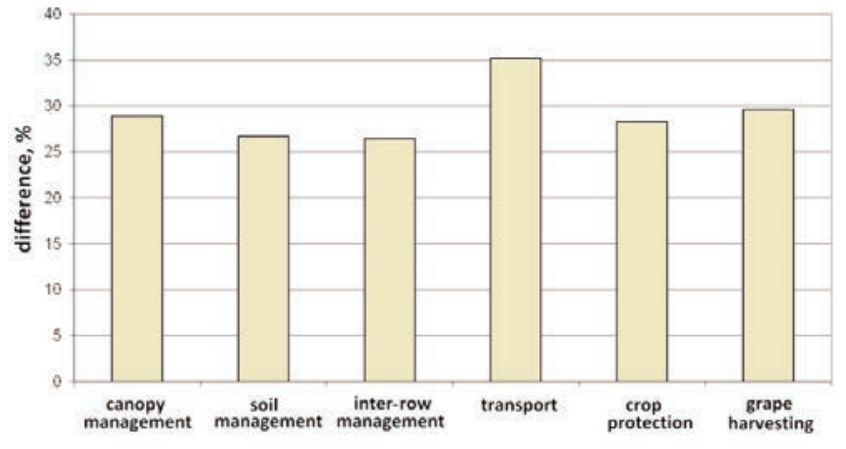

Figure 1. Difference between the "new" (highest single axis value) and the "old" (RMS value of the 3 axes) methods of vibration evaluation, referred to the $\mathbf{6}$ groups of similar tasks carried out in wine growing.

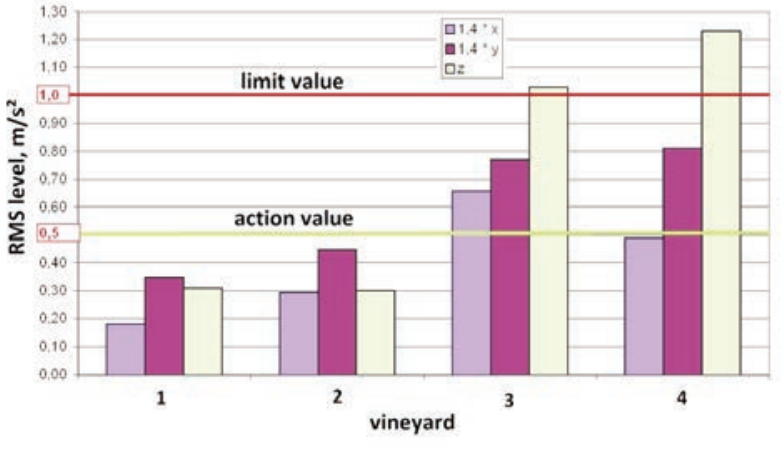

Figure 3. Vibration levels recorded in axes $x, y, z$ during the harrowing (cases 3 and 4) and hoeing (cases 1 and 2) all carried out with crawler tractors. 
On the contrary when hoeing the highest levels were recorded in y (lateral) axis, so stressing the work on uneven surface.

In the inter-row management, the chopping pruning, the suckering and the grass mowing were investigated in 13 wine farms. Especially grass mowing was performed in all the surveyed farms, because this is a task very frequently carried out more times during the year. Apart two or 3 situations, in fig. 4 the values are fairly similar. In 3 cases vibrations on $\mathrm{z}$ axis were above the limit value, but in many other they were very close to the lower limit of $0,5 \mathrm{~m} / \mathrm{s}^{2}$.

The levels in $\mathrm{x}$ axis (long) are often higher than those in $\mathrm{y}$ axis (lat): this is due to the technical characteristics of the pruning chopper, based on a rotor placed in a transversal direction in respect to the travelling, on which are running some tools in the longitudinal plane.

Due to the good number of measurements, it was possible to study the obtained data by dividing them between implements coupled only to the 3-point hitch and those having also some wheels (or other meanings) supporting the machine on the ground. In fact, in the first case the implement is entirely loading the tractor, while in the second the vibrations input could be transmitted in a different way to the driver's seat (fig. 5).

As expected, the situation is worsening if the pruning chopper has some meanings touching the ground: in the surveyed cases, at least one of the 3 axes exceeds the action value if $0,5 \mathrm{~m} / \mathrm{s} 2$, and in just an other in the $\mathrm{z}$ axis the remarkable level of $1.9 \mathrm{~m} / \mathrm{s}^{2}$ was reached.

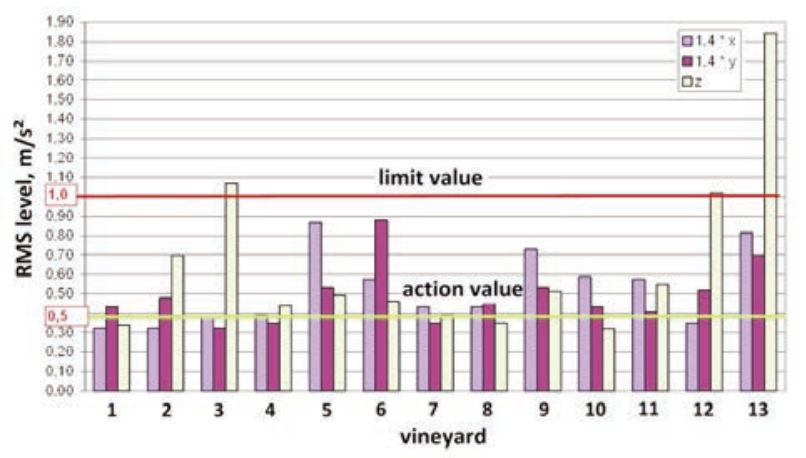

Figure 4. Vibration levels recorded in axes $\mathrm{x}, \mathrm{y}, \mathrm{z}$ during the chopping pruning combined with the grass mowing.
The measurements recorded in the inter-row management tasks were further examined regarding the tractor type used (in any case all of them had a power ranging from 60 and $130 \mathrm{CV}$ ). As expected, the fig. 6 shows a clear trend: with the wheeled tractors the vibration levels never exceed the limit value, but in most of them the action limit is reached in at least one of the axes. With the crawler tractors, the $\mathrm{Z}$ (vertical) axis levels are quite high.

For the crop protection (pesticide distribution, fig. 7) just in case $1 \mathrm{a}$ crawler tractor was used, showing vibration levels higher than all the other tests. In fact, on the sprayer used in vineyard the pump and the fan do not usually produce hazardous vibration levels, and therefore only the tractor is causing the disturbance.

In any case, the levels generally exceed the action value, but those recorded in the vertical axis are not the highest. The sprayers coupling was equally distributed between towed and hitched to the 3-point linkage.

Apart the case 8, the grape harvesting was executed manually (fig. 8 ); the measurements refer to the handling of the grape, in particular to the vibration on the seat of the tractor used for the transportation of the bins into the vineyard. On the grape harvester, the levels recorded were lower than the other 7 tractors surveyed, probably because they were all crawler tractors. In respect to the harvest carried out manually, the harvester assures a dramatic increase of the working capacity, but also better comfort conditions, included a lower vibration level.

The grape is normally transported from the wineyard to the cellar with single axle trailers (generally not exceeding $6 \mathrm{t}$ gross weight) towed with tractors. 4 wheeled tractors were investigated, ranging from 60 and $115 \mathrm{CV}$ (fig. 9). In two cases, the levels recorded on the vertical axis are within the action value, but only in one case all the 3 axes values were lower than this limit. In transportation, the travelling speed and the surface conditions are the most important factors influencing the vibrations. The levels in the transversal axis were higher than those in the longitudinal axis, proving that the soil unevenness produced in the surveyed cases more disturbance than the towed trailer input on the tractor.

\section{Operaor's exposure analysis}

With reference to the levels obtained from the similar group of tasks, an operator's exposure analysis was carried out, considering the usual reference of 8-hours working time (according to what specified in Italian Decree 81/08), although it is well known that the working day in agriculture is often much longer than this period. In particular, the values were compared with the action and limit values and the relevant limits of
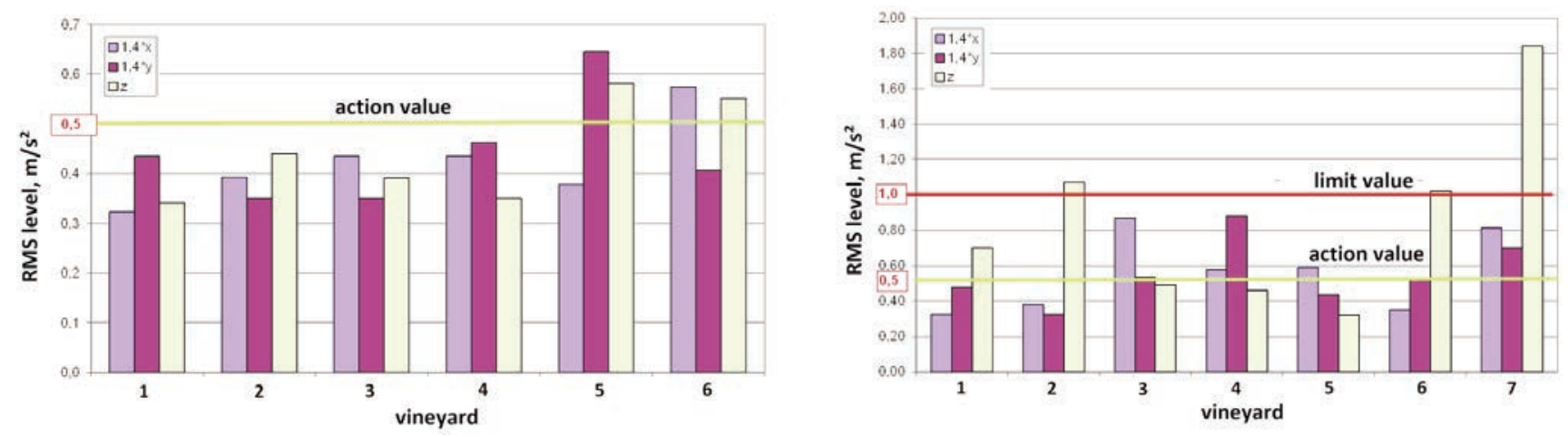

Figure 5. Vibration levels recorded in axes $x, y, z$ during the chopping pruning combined with the grass mowing, divided for implements coupled only to the 3-point hitch (left) and those having also some wheels or other meanings supporting the machine on the ground (right). 

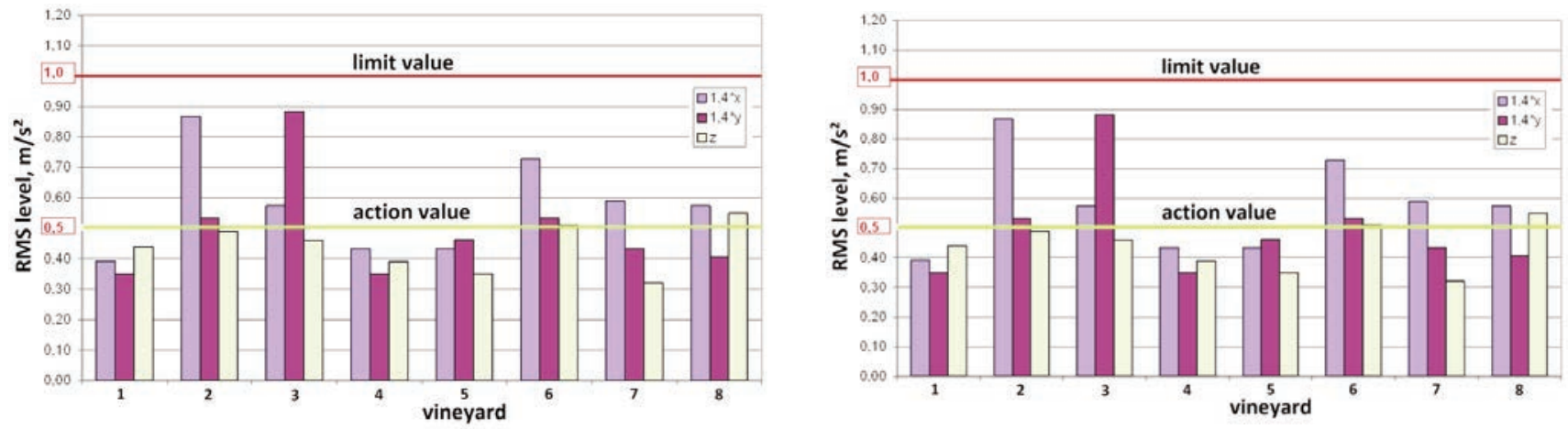

Figure 6. Vibration levels recorded in axes $\mathrm{x}, \mathrm{y}, \mathrm{z}$ during the chopping pruning combined with the grass mowing, divided for wheeled (left) and crawler (right) tractors.

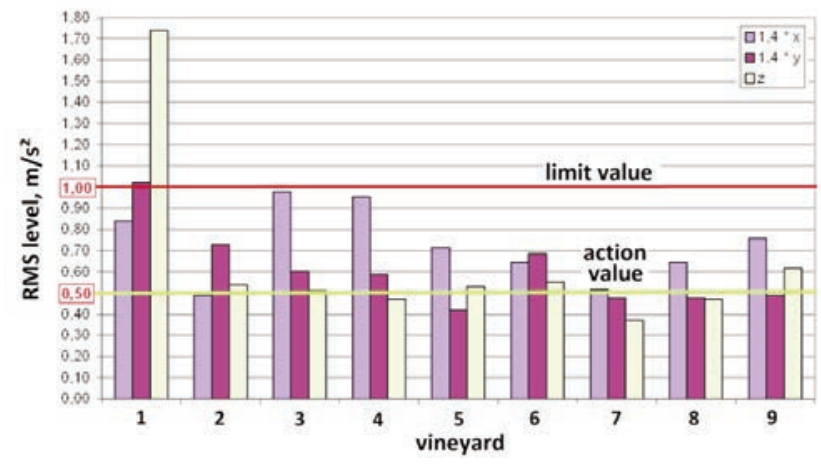

Figure 7. Vibration levels recorded in axes $x, y, z$ during the pesticide distribution.

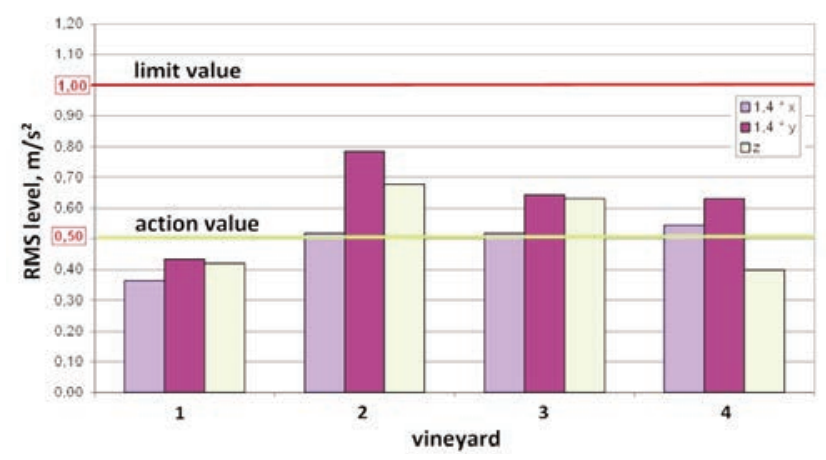

Figure 9. Vibration levels recorded in axes $x, y, z$ during the grape transportation with trailers on the road, from the vineyard to the cellar. In all the 4 cases surveyed, wheeled tractors were used.

working time were calculated, considering the average of the single figures obtained in the cases surveyed in each group of similar tasks.

The results (fig. 10) highlight the permissible working time to reach both the action $(0.5 \mathrm{~m} / \mathrm{s} 2)$ and the limit $(1.0 \mathrm{~m} / \mathrm{s} 2)$ values.

The transportation and the pesticide distribution tasks seem to be not critical: the limit value is not reached in 8-hours working time. On the contrary, for the soil management, the grape harvesting and the

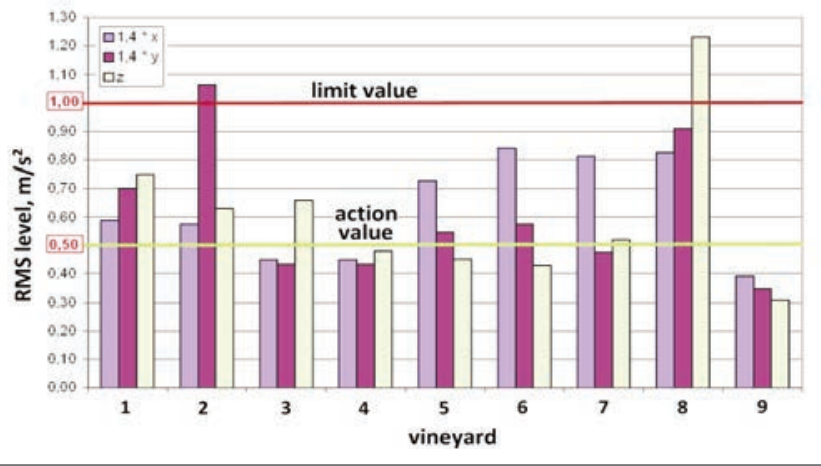

Figure 8. Vibration levels recorded in axes $\mathrm{x}, \mathrm{y}, \mathrm{z}$ during the grape harvesting. Cases 1 to 8 refer to a manual harvesting; case 9 is relevant to the use of a grape harvester.

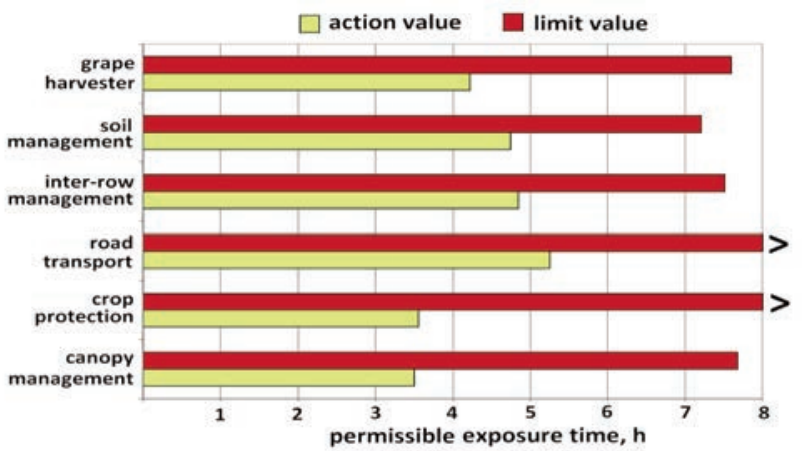

Figure 10. Permissible working time to reach the action (yellow) and limit (red) values of vibration, for 6 groups of similar tasks on wine growing.

inter-row management the operators should be stop their activity before the end of the working day.

On the other hand, the general situation appears more severe if the action value is considered: for all the tasks, this limit is reached rapidly, ranging from about 3.5 to 5 hours, so creating a lowering of the safety level, due to the increase of physical and mental fatigue of the operator. 


\section{Conclusions}

In general, the vibrations exposure of operators in wine growing does not appear dramatic for their physical health; however, the work concentration in some periods of the year definitely can lead to some dangerous situations, mainly due to the increase of physical and mental fatigue. In fact, referring to the most severe limit established by the 2002/44 EC Directive, the results show the opportunity to adopt some measures to reduce the vibration disturbance, especially in the vertical direction. The crawler tractors showed high vibrations, while the self-propelled machines (e.g. the grape harvester) highlighted a better level of comfort.

So, some actions could be profitably carried out to improve the situation: progressive replacement of crawler tractors with wheeled tractors;

- careful maintenance and adjusting of the driver's seat and its suspension system;

- frequent check of the correct tyre inflation pressure of the wheeled tractors and good maintenance of the track elements for the crawler tractors;

- check of the silent-blocks of the tractor cab or floor;

- careful maintenance of the implements to be attached to the tractor;

- task execution at a suitable travelling speed, not exceeding what provided by the manufacturer;

- assure a correct driving behaviour in transportation at high speed;

- suitable turn over of the tractor drivers, assuring them sufficient periods of rest, in order to recover the best physical and mental efficiency. 